[Agr. Biol. Ghem., Vol. 25, No. 9, p. 678 679, 1961]

\title{
Studies on the Synthesis of L-Amino Acids
}

\author{
Part III. A Synthesis of L-Homoserine from L-Aspartic Acid
}

\author{
By Masao TanaKa, Teruo KISHI and Shukuo Kinoshita \\ Tokyo Research Lab., Kyowa Hakko Kogyo Co., Ltd., Tokyo
}

Received May 11, 1961

\begin{abstract}
L-Homoserine was prepared by the reduction of $\mathrm{L}$-aspartic acid $\beta$-methyl ester with sodium borohydride in water solution without any racemization. The yield of L-homoserine was about $25 \%$ of the theoretical amount, and no product other than L-homoserine, L-aspartic acid and L-aspartic acid $\beta$-methyl ester was present in the reaction mixture. The low yield of $\mathrm{L}$-homoserine was ascribed to the hydrolysis of the ester.

L-Azetidine-2-carboxylic acid could not be detected in the reaction mixture. In contrast with the reduction of $\mathrm{L}$-glutamic acid $\gamma$-esters, the reduction of $\mathrm{L}$-aspartic acid $\beta$-ester was not accompanied by the cyclization.
\end{abstract}

L-Homoserine has been noted to be an important precursor for the biosynthesis of L-threonine, L-methionine and L-isoleucine. However, a method for the synthesis of $\mathrm{L}$ homoserine has been known only in a report ${ }^{1)}$ on a synthesis from L-glutamic acid via $L-\alpha, \gamma$ diaminobutyric acid, except the optical resolutions of DL-homoserine ${ }^{2 \sim 4)}$.

It was previously reported ${ }^{5)}$ that L-glutamic acid $\gamma$-esters were reduced and cyclized to $\mathrm{L}$ proline by treatment with sodium borohydride in water solution. The present paper reports that the ester group of $\mathrm{L}$-aspartic acid $\beta$-methyl ester was reduced to the hydroxyl group, and L-homoserine was formed by treatment with sodium borohydride.

Following the general method, L-aspartic acid $\beta$-methyl ester was obtained as hydrochloride from L-aspartic acid. The aqueous solution of the ester hydrochloride was neu-

\footnotetext{
1) H. Kawasaki, J, Chem. Soc. Japan, 81, 280 (1960).

2) M. D. Armstrong, J. Am. Chem. Soc, 70, 1756 (1948).

3) S. Weiss and J. A. Stekol, ibid., 73, 2497 (1951).

4) S. M. Birnbaum and J. P. Greenstein, Arch. Biochem. Biophys., 42, 212 (1953).

5) M. Tanaka, 'T. Kishi and S. Kinoshita, J. Agr. Chem. Soc. Japan, 34, 781 (1960).
}

tralized and added to the aqueous sodium borohydride solution. In the reaction mixture, not only L-homoserine but also the unchanged starting material and its hydrolized product, L-aspartic acid, were detected chromatographically, whereas no other ninhydrinpositive substances were found.

After desalting with ion exchangers, Lhomoserine in the reaction mixture was determined by a bioassay ${ }^{6}$. The amount of $\mathrm{L}$ homoserine was $25.5 \%$ of the theoretical.

After hydrolysis of the reaction mixture, the recovery of crystalline L-aspartic acid was $52 \%$ of the starting ester. These findings suggest that the ester was reduced to L-homoserine or hydrolyzed to L-aspartic acid.

After the desalting and the separation of the reaction mixture from aspartic acid, $L$ homoserine was isolated as $\gamma$-lactone hydrobromide by heating with hydrobromic acid. L- $\alpha$-Amino- $\boldsymbol{\gamma}$-butyrolactone hydrobromide was treated with a strong acidic cation exchanger to be free $\gamma$-lactone, and L-homoserine was

6) H. Samejima, 'T. Nara, 'T. Fujita and S. Kinoshita, ibid., 34, 750 (1960). 
obtained by hydrolyzation of the lactone.

After recrystallization, it was identified as L-homoserine by means of melting point, elemental analysis, optical rotation and bioassay.

This reduction yielded L-homoserine from L-aspartic acid without any change of the configuration.

In contrast with the reduction of L-glutamic acid $\gamma$-esters to $\mathrm{L}$-proline the reduction of $\mathrm{L}$ aspartic acid $\beta$-ester was not accompanied by the cyclization, and L-azetidine-2-carboxylic acid could not be detected in the reaction mixture. This difference is ascribed to the difficulty of the four-membered ring formation, compared with the five-membered ring formation in L-proline synthesis.

\section{EXPERIMENTAL}

\section{Analytical Procedure.}

Qualitative analysis was carried out by means of paper chromatography. The decending chromatography was run in a solvent system of $n$-butanol-acetic acid-water $(4: 1: 1)$ at room temperature, and the paper was dried and sprayed with $0.2 \%$ ninhydrin in aqueous $n$-butanol.

Quantitative determination of L-homoserine was made by bioassay with Escherichia coli 177-184, as described by Samejima et $a^{\text {e) }}$.

\section{Synthesis of L-Aspartic Acid $\beta$-Methyl ester Hydrochloride.}

$\mathrm{L}$-Aspartic acid $(82 \mathrm{~g})$ was dissolved in dry methanol $(500 \mathrm{ml})$ containing dry hydrogen chloride $(45 \mathrm{~g})$. After the concentration of the solution in vacuo at a temperature not higher than $40^{\circ} \mathrm{C}$, ether was added to the concentrate and stirred well. L-Aspartic acid $\beta$-methyl ester hydrochloride was then crystallized on cooling. Yield: $96.5 \mathrm{~g}$ ( $86 \%$ of the theoretical amount), m.p. $192^{\circ} \mathrm{C}$ (decomp.).

\section{Reduction of L-Aspartic Acid $\beta$-methyl Ester.}

L-Aspartic acid $\beta$-methyl ester hydrochloride $(36.7 \mathrm{~g}$ ) was dissolved in water $(50 \mathrm{ml})$, and neutralized with sodium bicarbonate. This aqueous solution was added to the solution of sodium borohydride $(10.6 \mathrm{~g})$ in water $(50 \mathrm{ml})$ dropwise with stirring, in the course of one hour at a temperature below $5{ }^{\circ} \mathrm{C}$. After the addition, the solution was stirred for additional two hours, then the temperature was raised to a room temperature and the solution was allowed to stand with stirring for another two hours to complete the reaction.

After neutralization of the reaction mixture with hydrochloric acid, amino acids and cations were adsorbed to a strong acidic cation exchanger, Diaion SK\# 1 (H-cycle), and eluted with $1 \mathrm{~N}$ ammonia solution. The eluate, from which ammonia was evaporated by means of concentration in vacuo, was passed through a strong basic anion exchanger, Diaion SA\# 201 (OH-cycle) and the amino acids were adsorbed. The eluate with $1 \mathrm{~N}$ hydrochloric acid contained L-homoserine and L-aspartic acid. L-Homoserine was determined by the bioassay. The amount of $\mathrm{L}$-homoserine in the reaction mixture was $6.1 \mathrm{~g}$ ( $25.5 \%$ of the theoretical amount) .

\section{Isolation and Identification of L-Homoserine.}

The desalted solution was evaporated to dryness in vacuo. The residue was dissolved in hot water (ca. $200 \mathrm{ml}$ ) and cooled to recover the crystallized L-aspartic acid $(8.5 \mathrm{~g})$. The filtrate was diluted with water to a liter, and L-aspartic acid was adsorbed from this solution to a weakly basic anion exchanger, Amberlite IR-4B (OH-cycle). Crystallized aspartic acid $(5.2 \mathrm{~g})$ was recovered from the eluate with $2 \%$ ammonia solution by concentration and cooling. The total amount of the recovered L-aspartic acid was $13.7 \mathrm{~g}$ and was equal to $52 \%$ of the starting ester.

The effluent containing L-homoserine was evaporated to dryness in vacuo, and $47 \%$ hydrobromic acid $(30 \mathrm{ml})$ was added to the residue. The solution was refluxed for two hours. After the solution was evaporated to dryness in vacuo, ethanol was added to the residue with stirring on a boiling water bath, then L- $\alpha$-amino- $\gamma$-butyrolactone hydrobromide was crystallized on cooling. The almost colorless crystals were filtered and washed with a small amount of ethanol and ether. Yield: $7.0 \mathrm{~g}$ (72\% of the formed L-homoserine), m.p. $235 \sim 8^{\circ} \mathrm{C}$ (decomp.).

The hydrobromide was dissolved in the water, and passed through a strong acidic cation exchanger, Diaion SK \#1 (H-cycle), to adsorb the free lactone and its hydrolyzed product homoserine.

After the concentration of the eluate with $1 \mathrm{~N} \mathrm{am}$. monia solution in vacuo, ethanol was added to the concentrate to crystallize free L-homoserine.

Recrystallized from aqueous ethanol, m.p. $203^{\circ} \mathrm{C}$ $[\alpha]_{\mathrm{D}}^{15}=-8.2^{\circ} \quad(2 \%$ aqueous solution $)$.

Anal. Found: C, 40.56; H, 7.13; N, 11.48. Calcd. for $\mathrm{C}_{4} \mathrm{H}_{0} \mathrm{NO}_{3}:$ C, $40.33 ; \mathrm{H}, 7.62 ; \mathrm{N}, 11.76 \%$. 